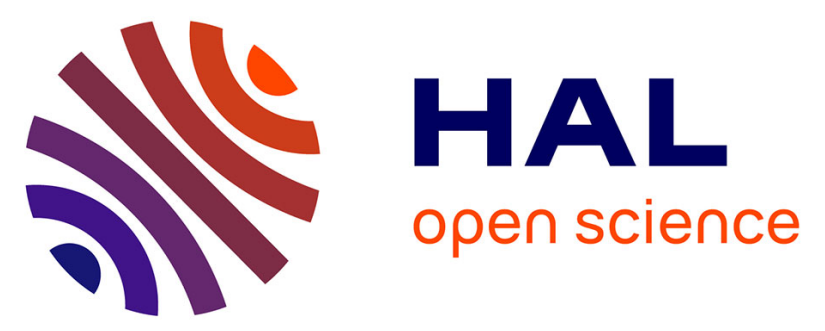

\title{
Methodological approach for the detection of both microdamage and fluorochrome labels in ewe bone and human trabecular bone
}

Brigitte Burt-Pichat, Hélène Follet, Gwendoline Toulemonde, Monique E. Arlot, Pierre D. Delmas, Roland D. Chapurlat

\section{To cite this version:}

Brigitte Burt-Pichat, Hélène Follet, Gwendoline Toulemonde, Monique E. Arlot, Pierre D. Delmas, et al.. Methodological approach for the detection of both microdamage and fluorochrome labels in ewe bone and human trabecular bone. Journal of Bone and Mineral Metabolism, 2011, 29 (6), pp.756-764. 10.1007/s00774-011-0291-7 . hal-01183701

\section{HAL Id: hal-01183701 https://hal.science/hal-01183701}

Submitted on 6 Nov 2019

HAL is a multi-disciplinary open access archive for the deposit and dissemination of scientific research documents, whether they are published or not. The documents may come from teaching and research institutions in France or abroad, or from public or private research centers.
L'archive ouverte pluridisciplinaire HAL, est destinée au dépôt et à la diffusion de documents scientifiques de niveau recherche, publiés ou non, émanant des établissements d'enseignement et de recherche français ou étrangers, des laboratoires publics ou privés. 


\title{
Methodological approach for the detection of both microdamage and fluorochrome labels in ewe bone and human trabecular bone
}

\author{
Brigitte Burt-Pichat $\cdot$ Hélène Follet $\cdot$ \\ Gwendoline Toulemonde • Monique Arlot • \\ Pierre Delmas $\cdot$ Roland Chapurlat
}

Received: 25 January 2011/ Accepted: 5 June 2011

(C) The Japanese Society for Bone and Mineral Research and Springer 2011

\begin{abstract}
The purpose of this study was to adapt various staining methods for the detection of microdamage in human bone, while preserving tetracycline labels. We describe two staining methods using calcein green and xylenol orange, first developed in ewe bone samples and validated in human trabecular bone samples. In ewe bones, we found that calcein green at $0.5 \mathrm{mM}$ concentration diluted in $100 \%$ ethanol as well as xylenol orange at $5 \mathrm{mM}$ were the most adequate fluorochromes both to detect microdamage and preserve the double tetracycline labeling. These results were verified in human trabecular bone (iliac crest for the tetracycline label, and vertebral bone for the double labeling). Results obtained in human bone samples were identical to those in ewes, so this combination of fluorochromes is now used in our laboratory.
\end{abstract}

Keywords Microdamage - Fluorescent labels - Ewe iliac crest $\cdot$ Human trabecular bone

\section{Introduction}

Loading of bone induces in vivo linear and diffuse microdamage [1-10]. The propensity of bone to form linear and diffuse damage varies with age and the two forms of

B. Burt-Pichat · H. Follet - G. Toulemonde - M. Arlot ·

P. Delmas · R. Chapurlat

INSERM, UMR1033, 69008 Lyon, France

B. Burt-Pichat · H. Follet · G. Toulemonde - M. Arlot ·

P. Delmas - R. Chapurlat

Université de Lyon, UMR1033, 69008 Lyon, France

H. Follet $(\bowtie)$

INSERM, UMR1033, Faculté de Médecine Lyon Est (domaine

Laennec), 7-11 Rue G. Paradin, 69008 Lyon, France

e-mail: Helene.Follet@inserm.fr microdamage have different effects on the mechanical properties of bone and influence skeletal fragility [11-14]. Microdamage has been largely studied in compact bone [13, 1522] but less in human trabecular bone [5, 23-28]. To date, two main standard methods to stain bone for microdamage detection have been described: (1) the basic fuchsin bulk staining used to detect microdamage generated in vivo [2, 6 , $19,25,29,30]$, and (2) the use of fluorescent chelating agents $[16,17,19,31,32]$. In addition to distinguishing fully-stained microcracks generated in vivo from partially-stained or artifactual-stained cracks due to cutting and/or machining, one of the challenges is to identify and quantify microdamage in human trabecular bone without washing previous labels used for histomorphometry and qualitative bone histology.

The aims of this study were to develop a methodological approach, based on previous work [2, 3, 6, 16, 17, 19, 29, 31 , to accurately identify microdamage in trabecular bone without erasing fluorescent labels such as tetracycline. This approach has also made it possible to distinguish preexisting true from artifactual microdamage and damage from mechanical testing. We describe here a double labeling method using two different fluorochromes that was developed on ewe bone samples and then validated on human trabecular bone samples.

\section{Materials and methods}

The methods were developed in ewe bone and then applied to human trabecular bone.

Preparation of ewe bone

Fifty transiliac bone biopsies were obtained after tetracycline labeling from ewes under local anesthesia, with a 
Fig. 1 Preparation of transiliac bone biopsies from ewes

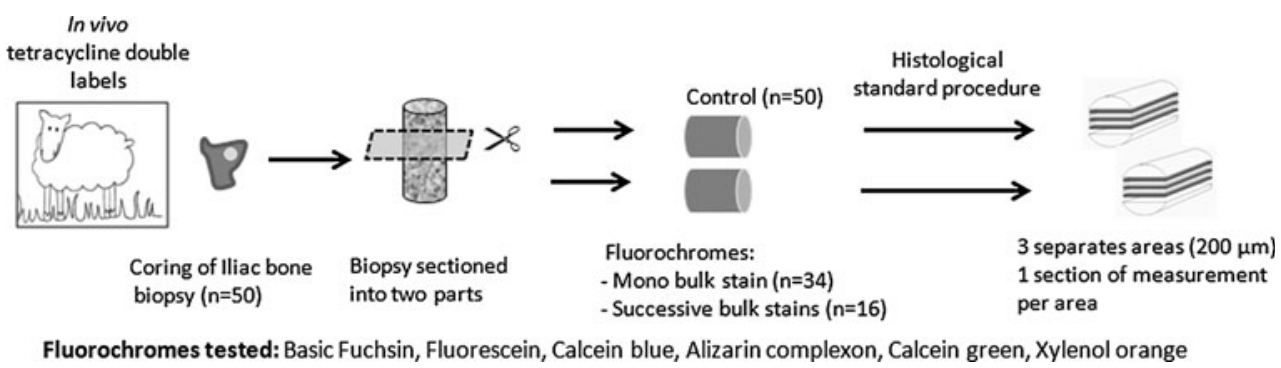

Preparation of human trabecular bone

7.5-mm internal diameter trephine, $2 \mathrm{~cm}$ behind the anterosuperior iliac spine and $2 \mathrm{~cm}$ below the iliac crest edge (Fig. 1) [33]. To rule out artifactual microdamage, bone samples needed to be stained before and after cutting the sections. Biopsies were then separated into two parts. One half served as a control to observe double labeling on unstained sections, and the other half served for the fluorochrome tests.

To quantify the correct concentration, dilution and time limit for detecting both microdamage and labels, 34 halfbiopsies were bulk-stained separately at room temperature with the following fluorochromes (Table 1; Fig. 2): basic fuchsin ${ }^{1}(\mathrm{BF}), n=1$; fluorescein, ${ }^{2} n=12$; calcein blue, $^{3}$ $n=4$; alizarin complexone, ${ }^{4} n=2$; calcein green, ${ }^{5} n=6$; and xylenol orange, ${ }^{6} n=9$. All tests were performed either in ethanol or a water-based solution and different concentrations and duration of bulk staining were tested for each fluorochrome (Table 1). To verify that fluorochrome staining did not alter classical histological stains, a few supplementary sections were cut for Goldner's trichrome, Solochrome cyanin R, May-Grünwald-Giemsa and Toluidine blue [34].

To assess the double labeling study, 16 half-biopsies were processed (Table 2). Two successive bulk stainings were performed at room temperature on the same sample, combining basic fuchsin, fluorescein, xylenol orange and calcein green (Table 2). We considered basic fuchsin as the staining reference. For this, bone samples were bulkstained in $1 \%$ basic fuchsin in 70, 80, 90, and $100 \%$ ethanol under vacuum at 15-20 $\mathrm{mmHg}$ for $4 \mathrm{~h}$ each. After staining, core samples were fixed in $70 \%$ ethanol, rinsed in $100 \%$ ethanol and embedded in methyl methacrylate [6, 34, 35].

The best staining results obtained on ewes were used on human trabecular bone.

\footnotetext{
${ }^{1}$ B660-30 JT Baker, Phillipsburg, NJ, USA.

${ }^{2}$ F 6377 Sigma Chemical Co., St Louis, MO, USA.

3 M1255 Sigma.

4 A3882 Sigma.

5 C 0875 Sigma.

6398187 Sigma.
}

\section{Transiliac bone biopsies}

Fifty postmenopausal osteoporotic women who had been on bisphosphonates were recruited from the outpatient clinic. Transiliac bone biopsies were performed after all patients were double-labeled with demethylchlortetracycline. Theses samples were used to verify and validate the effect of fluorochromes on double tetracycline labels [36].

\section{Vertebral bone cores}

Six human vertebrae (3L2 and 3L4) obtained from recently deceased donors were bulk-stained for 11 days at room temperature in $5 \mathrm{mM}$ xylenol orange based in $70 \%$ ethanol [37, 38]. After staining, a 8.25-mm diameter cylindrical trabecular specimen was removed using a diamond-tipped coring tool. To detect the induced microdamage, trabecular cores were bulk-stained for 2 days in $0.5 \mathrm{mM}$ green calcein based in $100 \%$ ethanol and thereafter embedded in methyl methacrylate. Theses samples were used to verify the double labeling of fluorochromes for the detection of microdamage.

\section{Preparation for histomorphometry}

All undecalcified bones were cut along the long axis at very low speed using a heavy-duty microtome (Polycut E, Leica Microsystems, Wetzlar, Germany) equipped with tungsten carbide knives to obtain at least three non-contiguous, parallel, $100 \pm 5 \mu \mathrm{m}$ sections for detection of microcracks. Several consecutive $8-\mu \mathrm{m}$ sections were cut to measure bone trabecular volume and area, and also to be used afterwards to test the classical histological staining procedures. Sections were then mounted between microscope slides and cover glasses with a mounting medium (NeoEntellan $^{\circledR}$, Merck, Germany).

Microdamage detection and analysis

Microdamage was detected by optical microscopy (Carl Zeiss, Germany) under fluorescent light at $\times 200$ 
Table 1 Staining tests performed $(n=34)$ with chelating agents including concentration, bulk staining time and final result for the detection of both microdamage and labels

\begin{tabular}{|c|c|c|c|c|c|c|c|}
\hline \multirow[t]{2}{*}{ Agent } & \multirow[t]{2}{*}{ Dilution } & \multirow[t]{2}{*}{ Concentration } & \multirow[t]{2}{*}{ Time } & \multicolumn{3}{|l|}{ Results } & \multirow{2}{*}{$\begin{array}{l}\text { Final } \\
\text { results }\end{array}$} \\
\hline & & & & $\begin{array}{l}\text { Crack } \\
\text { stained }\end{array}$ & $\begin{array}{l}\text { Crack } \\
\text { measurable }\end{array}$ & $\begin{array}{l}\text { Visibility of } \\
\text { previous label }\end{array}$ & \\
\hline Basic fuchsin & Ethanol & $1 \%$ & $24 \mathrm{~h}$ & ++ & ++ & + & + \\
\hline \multirow[t]{12}{*}{ Fluorescein } & Ringer's solution & $12 \%$ & $24 \mathrm{~h}$ & +++ & + & --- & - \\
\hline & & $12 \%$ & $12 \mathrm{~h}$ & + & --- & --- & --- \\
\hline & & & $60 \min$ & + & --- & --- & --- \\
\hline & & & $30 \min$ & + & --- & --- & --- \\
\hline & & $6 \%$ & $24 \mathrm{~h}$ & + & --- & --- & --- \\
\hline & & $3 \%$ & $24 \mathrm{~h}$ & + & --- & --- & --- \\
\hline & Ethanol $100 \%$ & $12 \%$ & $24 \mathrm{~h}$ & +++ & + & --- & --- \\
\hline & & $12 \%$ & $12 \mathrm{~h}$ & + & - & --- & --- \\
\hline & & & $60 \mathrm{~min}$ & + & - & --- & --- \\
\hline & & & $30 \min$ & + & - & --- & --- \\
\hline & & $6 \%$ & $24 \mathrm{~h}$ & + & - & --- & --- \\
\hline & & $3 \%$ & $24 \mathrm{~h}$ & + & - & --- & --- \\
\hline \multirow[t]{4}{*}{ Calcein blue } & Water & $10 \mathrm{mM}$ & $12 \mathrm{~h}$ & - & - & + & + \\
\hline & & $0.1 \mathrm{mM}$ & $2 \mathrm{~h}$ & ++ & ++ & - & - \\
\hline & Ethanol $100 \%$ & $10 \mathrm{mM}$ & $12 \mathrm{~h}$ & - & - & + & + \\
\hline & & $0.1 \mathrm{mM}$ & $2 \mathrm{~h}$ & ++ & ++ & - & - \\
\hline \multirow[t]{2}{*}{ Alizarin complexone } & Water & $0.5 \mathrm{mM}$ & $2 \mathrm{~h}$ & +++ & +++ & + & + \\
\hline & Ethanol $100 \%$ & $0.5 \mathrm{mM}$ & $2 \mathrm{~h}$ & +++ & +++ & ++ & ++ \\
\hline \multirow[t]{6}{*}{ Calcein green } & Tris $\mathrm{HCl} 0.5 \mathrm{M}$ & $0.5 \mathrm{mM}$ & $12 \mathrm{~h}$ & - & - & - & - \\
\hline & & & $2 \mathrm{~h}$ & +++ & +++ & + & ++ \\
\hline & Water & $0.5 \mathrm{mM}$ & $12 \mathrm{~h}$ & - & - & - & - \\
\hline & & & $2 \mathrm{~h}$ & +++ & +++ & + & ++ \\
\hline & Ethanol $100 \%$ & $0.5 \mathrm{mM}$ & $12 \mathrm{~h}$ & - & - & - & - \\
\hline & & & $2 \mathrm{~h}$ & +++ & +++ & +++ & +++ \\
\hline \multirow[t]{9}{*}{ Xylenol orange } & Tris $\mathrm{HCl} 0.5 \mathrm{M}$ & $1 \%$ & $2 \mathrm{~h}$ & - & - & - & - \\
\hline & Water & $5 \mathrm{mM}$ & $12 \mathrm{~h}$ & - & - & - & - \\
\hline & & & $2 \mathrm{~h}$ & +++ & +++ & + & ++ \\
\hline & & $0.5 \mathrm{mM}$ & $12 \mathrm{~h}$ & - & - & + & - \\
\hline & & & $2 \mathrm{~h}$ & - & - & + & - \\
\hline & Ethanol $100 \%$ & $5 \mathrm{mM}$ & $12 \mathrm{~h}$ & - & - & - & - \\
\hline & & & $2 \mathrm{~h}$ & +++ & +++ & +++ & +++ \\
\hline & & $0.5 \mathrm{mM}$ & $12 \mathrm{~h}$ & - & - & +++ & - \\
\hline & & & $2 \mathrm{~h}$ & - & - & +++ & - \\
\hline
\end{tabular}

+ , weak results; ++ , acceptable results; +++ , excellent results; - , no result; --- , excessive results

magnification and using morphometry software (Bone Morpho; Explora Nova, La Rochelle, France). Microdamage was observed using several specific filters at excitation/ emission wavelengths of 440/610 nm (Filter set \#20 $0^{7}$ from Zeiss), $495 / 520 \mathrm{~nm}$ (Filter set $\# 09^{8}$ from Zeiss) and

\footnotetext{
${ }^{7}$ Filter set \#20: Excitation BP 546/12, Beam Splitter FT 560, Emission BP 575-640.

${ }^{8}$ Filter set \#09: Excitation BP 450-490, Beam Splitter FT 510, Emission LP 515.
}

390/590 nm (Filter set $\# 18^{9}$ from Zeiss) (Table 3). To avoid artifactual cutting damage, the region of measurement was located $<0.8 \mathrm{~mm}$ from any cutting edge. Microdamage was categorized and quantified as linear microcracks or diffuse damage. Outcome assessments included the number of linear cracks (Cr.N, \#), the number of diffuse damage areas (Dx.N, \#), the linear crack density,

\footnotetext{
${ }^{9}$ Filter set \#18: Excitation BP 390-420, Beam Splitter FT 425, Emission LP 450.
} 

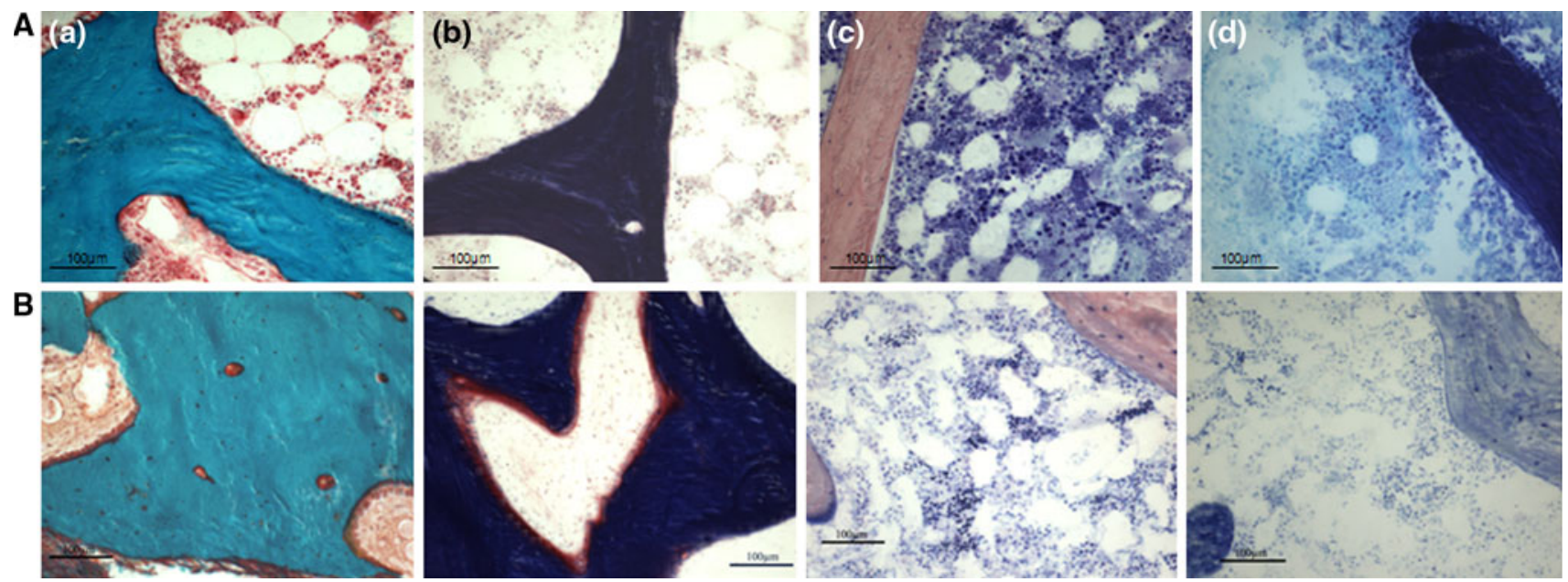

Fig. 2 All chelating agents preserved the quality of classical histomorphometric staining: A shows the classical histomorphometry stain: $a$ Goldner's trichrome, $b$ Solochrome cyanin $\mathrm{R}, c$ May-

Grünwald-Giemsa, $d$ Toluidine blue, and $\mathbf{B}$ shows the corresponding stains after bulk staining by calcein green

Table 2 Two successive bulk stainings were performed on each sample $(n=16)$

\begin{tabular}{llll}
\hline$n$ & Fluorochrome no. 1 & Fluorochrome no. 2 & Results \\
\hline 1 & Fluorescein & Basic fuchsin & Xylenol orange (water) \\
2 & Basic fuchsin & Xylenol orange (water) \\
3 & Calcein green (ethanol) & Basic fuchsin & --- \\
4 & Calcein green (ethanol) & Basic fuchsin & +++ \\
5 & Xylenol orange (ethanol) & Calcein green (water) \\
6 & Xylenol orange (water) & Calcein green (ethanol) \\
7 & Xylenol orange (water) & Calcein green (water) \\
8 & Xylenol orange (ethanol) & Calcein green (ethanol) & +++ \\
\hline
\end{tabular}

Only 9 of 16 biopsies presented interpretable microcracks. Final results on the ability to see microcracks are presented. Assays retained are shown in italics: xylenol orange followed by calcein green (ethanol)

+++ , excellent results; + , weak results; --- , excessive results

Table 3 Dilution, concentration, wavelength and filter used for optimum results in microdamage detection

\begin{tabular}{llllll}
\hline Agent & Dilution & Concentration & $\begin{array}{l}\text { Excitation } \\
\text { wavelength }\end{array}$ & $\begin{array}{l}\text { Emission } \\
\text { wavelength }\end{array}$ & Filter \\
\hline Basic fuchsin & Ethanol 100\% & $1 \%$ & 608 & 631 & Green \\
Fluorescein & Ringer's solution & $12 \%$ & 460 & 515 & Green \\
Alizarin complexone & Ethanol 100\% or water & $0.5 \mathrm{mM}$ & 580 & 625 & Red \\
Calcein blue & Ethanol 100\% or water & $0.1 \mathrm{mM}$ & 375 & 435 & Blue \\
Calcein green & Ethanol 100\% or water & $0.5 \mathrm{mM}$ & 495 & 520 & Green \\
Xylenol orange & Ethanol 100\% or water & $5 \mathrm{mM}$ & 440,570 & 610 & Orange
\end{tabular}

$\mu \mathrm{m} / \mathrm{mm}^{2}$ ) and diffuse damage area density defined as diffuse damage area per bone area (Dx.Ar.Dn, \%). The reproducibility of microdamage identification was assessed by two observers independently analyzing five sections from five different donors. They identified 35 and 32 microcracks, respectively, 31 of which were concordant, providing a Kappa score of 0.77 . A Kappa score is always 
$\leq 1$. A value of 1 implies perfect agreement and values $<1$ imply less than perfect agreement. In our study, a result between 0.60 and 0.80 indicated a good agreement. The reproducibility of linear microcrack length and diffuse damage area measurements were assessed by two observers on 25 microcracks and/or diffuse damage regions. The intraclass correlation coefficients for both length and area measurements were 0.99 .

\section{Results}

Ewe bone

Two of the six fluorochromes used to evaluate the best microcrack labeling were not satisfactory (Table 1). With fluorescein, microcracks were visible but tetracycline labeling (double labeling) faded and the bone area was partly covered with fluorochrome. With calcein blue staining, at low concentrations, double labeling (tetracycline) was visible but not the microdamage whereas at high concentrations, cracks were visible but double labeling was faint (histomorphometry measurement unavailable). Optimal results in dilution, concentration, wavelength and filter for microdamage detection are presented in Table 3. The classical histomorphometric stains (Goldner's trichrome, Solochrome cyanin R, May-Grünwald-Giemsa and Toluidine blue) were preserved after bulk staining by all the chelating agents. Four sections stained by classical stains after calcein green bulk staining are presented in Fig. 2. In Goldner's staining, osteoid still appears redorange and mineralized bone green appears as before bulk staining (Fig. 2a). Solochrome cyanin R staining, which is a reliable stain giving an unequivocal identification of osteoid, calcified matrix and bone cells, is still valid with the calcified bone appearing in a uniform dark blue color and osteoid in red (Fig. 2b), and osteons are still visible in polarized light. May-Grünwald-Giemsa staining still distinguished bone marrow cells after bulk staining in calcein green (Fig. 2c). Toluidine blue still stained cells, nuclei and osteoid but the calcified bone matrix remained almost unstained (Fig. 2d). Two successive bulk stainings were performed on the same sample combining basic fuchsin, fluorescein, xylenol orange and calcein green (Table 2). Several combinations of fluorochromes allowed the detection of both the microdamage and the tetracycline. One of the best combinations was xylenol orange followed by calcein green (in aqueous or alcoholic solutions); however, aqueous solutions tended to decrease the visibility of previous labels (Table 1).

We also compared Cr.Le measurements after bulk staining by the reference, basic fuchsin, followed by calcein green (Table 4a) or xylenol orange (data not shown).
Assessment of the analyzed microdamage was similar in sections stained with both basic fuchsin and calcein green or xylenol orange. Cracks stained by basic fuchsin were longer than those stained by calcein green. For example, among seven microcracks from the same sample, we found a mean difference at $-2.01 \mu \mathrm{m}$ (ranging from -0.68 to $-6.66 \mu \mathrm{m}$ ), and a relative error in the microcrack length between -0.37 and $-4.34 \%$ with a mean at $-1.98 \%$, between the measurements (Table 4a). A highly significant correlation was also observed between the two measurements $(r=0.999, p<0.001)$. We compared the length of the microcracks stained by calcein green with those stained by xylenol orange in the same samples (Table 4b). On the same sample, 8 microcracks stained by calcein green appeared to be longer than those stained by xylenol orange. These data showed a difference between -3.12 and $12.42 \mu \mathrm{m}$ with a mean of $+1.55 \mu \mathrm{m}$, and a relative error between -11.02 and $12.90 \%$ with a mean of $+0.95 \%$ (Table 4b). There was no significant difference between the lengths measured with the two fluorochromes and a highly significant correlation was observed between the two measurements $(r=0.967, p<0.001)$.

Our result on ewes showed that calcein green at $0.5 \mathrm{mM}$ concentration diluted in $100 \%$ ethanol as well as xylenol orange at $5 \mathrm{mM}$ were the most adequate fluorochromes to detect both microdamage and to preserve the double tetracycline labeling. Examples are shown in Fig. 3. These stains were then checked on human trabecular bone.

\section{Human bone}

In iliac trabecular bone, results were consistent with those on ewes showing that the same cracks could be stained by several dyes; all microcracks stained with basic fuchsin were also observed with calcein green. Only one cross-hatched microcrack and one area of diffuse microcracks were observed. The mean cancellous bone microcrack length was $120 \mu \mathrm{m}$.

In vertebral trabecular bone, both fluorochromes (xylenol and calcein) were distinguishable using two wavelength filters. Because all vertebrae were bulk-stained with xylenol orange and with calcein before and after cylindrical specimen preparation, respectively, the microdamage stained with xylenol orange means they were present in vivo, and those stained with calcein green were produced from drilling and sectioning. In vivo, Cr.Dn was significantly greater than artifactual damage $(1.49 \pm 1.25$ vs. $\left.0.41 \pm 0.35 \# / \mathrm{mm}^{2} ; p=0.003\right)$.

\section{Discussion}

The purpose of this study was to adapt several staining methods developed by Norman, Schaffler, Burr, Lee, and 
Table 4 Examples of results on two successive bulk stainings (same sections, same crack, with two different filters): quantification of microcracks length stained in calcein green (excitation/emission wavelength of $495 / 520 \mathrm{~nm}$ ) compared to microcrack length stained with: (a) 1st sample: basic fuchsin (transmitted light), and (b) 2nd sample: xylenol orange (excitation/emission wavelength of $440 / 610 \mathrm{~nm}$ )

(a) A mean difference of $\sim 2 \mu \mathrm{m}$ is found in the linear microcracks length between the two stains, but a significant correlation is observed ( $r=0.999, p<0.001$ ).

(b) A mean difference of $\sim 1.6 \mu \mathrm{m}$ is found in the linear microcracks length between the two stains but a significant correlation is observed $(r=0.967, p<0.001)$

\begin{tabular}{|c|c|c|c|c|}
\hline (a) & $\begin{array}{l}\text { Crack length } \\
\text { Calcein green }(\mu \mathrm{m})\end{array}$ & $\begin{array}{l}\text { Crack length } \\
\text { Basic fuchsin }(\mu \mathrm{m})\end{array}$ & Difference $(\mu \mathrm{m})$ & Relative error (\%) \\
\hline \multicolumn{5}{|l|}{$n=7$} \\
\hline 1 & 55.62 & 56.30 & -0.68 & -1.22 \\
\hline 2 & 74.06 & 75.63 & -1.57 & -2.12 \\
\hline 3 & 27.91 & 29.12 & -1.21 & -4.34 \\
\hline 4 & 209.93 & 216.59 & -6.66 & -3.17 \\
\hline 5 & 97.47 & 99.53 & -2.06 & -2.11 \\
\hline 6 & 207.25 & 208.01 & -0.76 & -0.37 \\
\hline 7 & 208.90 & 210.05 & -1.15 & -0.55 \\
\hline Mean & 125.9 & 127.9 & -2.01 & -1.98 \\
\hline SD & 80.2 & 81.1 & 2.1 & 1.43 \\
\hline (b) & $\begin{array}{l}\text { Crack length } \\
\text { Calcein green }(\mu \mathrm{m})\end{array}$ & $\begin{array}{l}\text { Crack length } \\
\text { Xylenol }(\mu \mathrm{m})\end{array}$ & Difference $(\mu \mathrm{m})$ & Relative error (\%) \\
\hline \multicolumn{5}{|l|}{$n=8$} \\
\hline 1 & 58.27 & 54.87 & 3.4 & 5.83 \\
\hline 2 & 85.49 & 84.23 & 1.26 & 1.47 \\
\hline 3 & 66.86 & 74.23 & -7.37 & -11.02 \\
\hline 4 & 42.46 & 45.58 & -3.12 & -7.35 \\
\hline 5 & 128.34 & 121.62 & 6.72 & 5.24 \\
\hline 6 & 72.13 & 79.22 & -7.09 & -9.83 \\
\hline 7 & 59.77 & 53.59 & 6.18 & 10.34 \\
\hline 8 & 96.25 & 83.83 & 12.42 & 12.90 \\
\hline Mean & 76.20 & 74.65 & 1.55 & 0.95 \\
\hline SD & 27.63 & 25.78 & 7.03 & 8.55 \\
\hline
\end{tabular}

O'Brien et al. [2, 3, 6, 16, 17, 19, 29, 31] to our specific aim, i.e., the detection of both microdamage and fluorochrome labels (tetracycline) in human bones. Most of the previous tests using several dyes were performed on cortical bone. The novelty of our study was the use of several fluorochromes to detect microdamage in trabecular bone without deleting fluorochrome labels, with a large study in ewes and validation in human bones used in clinical practice (iliac bone).

Fluorochromes are calcium binding substances that are preferentially taken up at the site of active mineralization of bone, also known as the calcification front. Sun et al. [39] found no differences between either of the non-tetracycline labels (xylenol orange and calcein green) for any of the histomorphometric measurements. In our study, we found that, compared to the basic fuchsin staining, microcracks measured by calcein green were slightly smaller in length (mean $2 \mu \mathrm{m}$ ), but both measurements were highly correlated. This could be due to the fact that fuchsin-stained microcracks were measured under transmitted light. Lee et al. compared fuchsin-stained microcracks in human rib bones using transmitted light and epifluorescence microscopy. They found no differences between the two methods in crack number, density or length indicating comparable accuracy [17], suggesting that our epifluorescence microscopy measurements could have provided similar results. The mean difference between the microcrack length observed with calcein green bulk staining followed by xylenol orange was $1.55 \mu \mathrm{m}$ in our study, without predominance of one stain on the length of the microcracks. This difference is too small to be clinically relevant. Comparatively, in compact bone, Lee et al. [31] found that the length [mean (SD)] of microcracks in ten rib bones was $70.30(46.87) \mu \mathrm{m}$ in calcein green and $62.58(46.45) \mu \mathrm{m}$ in xylenol orange without a significant difference. O'Brien et al. provided one possible explanation about the length difference between the two fluorochromes. They measured the affinity of chelating agents for $\mathrm{Ca}^{2+}$ ions with chromatography and found that the mean height of calcium peak was higher in calcein green (0.945) than xylenol orange (0.88). The smallest number (xylenol, 0.88) indicated a greater affinity for calcium than calcein green [40]. Alternatively, as these differences were small, they may stem from measurement variability and would therefore not be significant.

In our study, we also found little diffuse damage in both ewe bones and human iliac bones. This could be due to the fact that, in both cases, the iliac bone is not a weight-bearing bone. Moreover, $>50 \%$ of human bone biopsies had no visible trabecular bone microcracks. In 
Fig. 3 Examples of successive staining on ewes using several filters: $\mathbf{a}$ and $\mathbf{b}$ microcrack stained by basic fuchsin stays visible after calcein green staining using a 546/640 filter (Filter set \#20), c and d double tetracycline label (down) and a microcrack (upper) are visible using a 390/450 filter (Filter set \#18) but only microdamage (upper) remains visible after fluorescein staining using a 450/515 filter (Filter set \#09), $\mathbf{e}$ and $\mathbf{f}$ microcrack stained in alizarin using a 546/640 filter (Filter set \#20) is no longer visible (right) with a 450/515 filter (Filter set \#09)
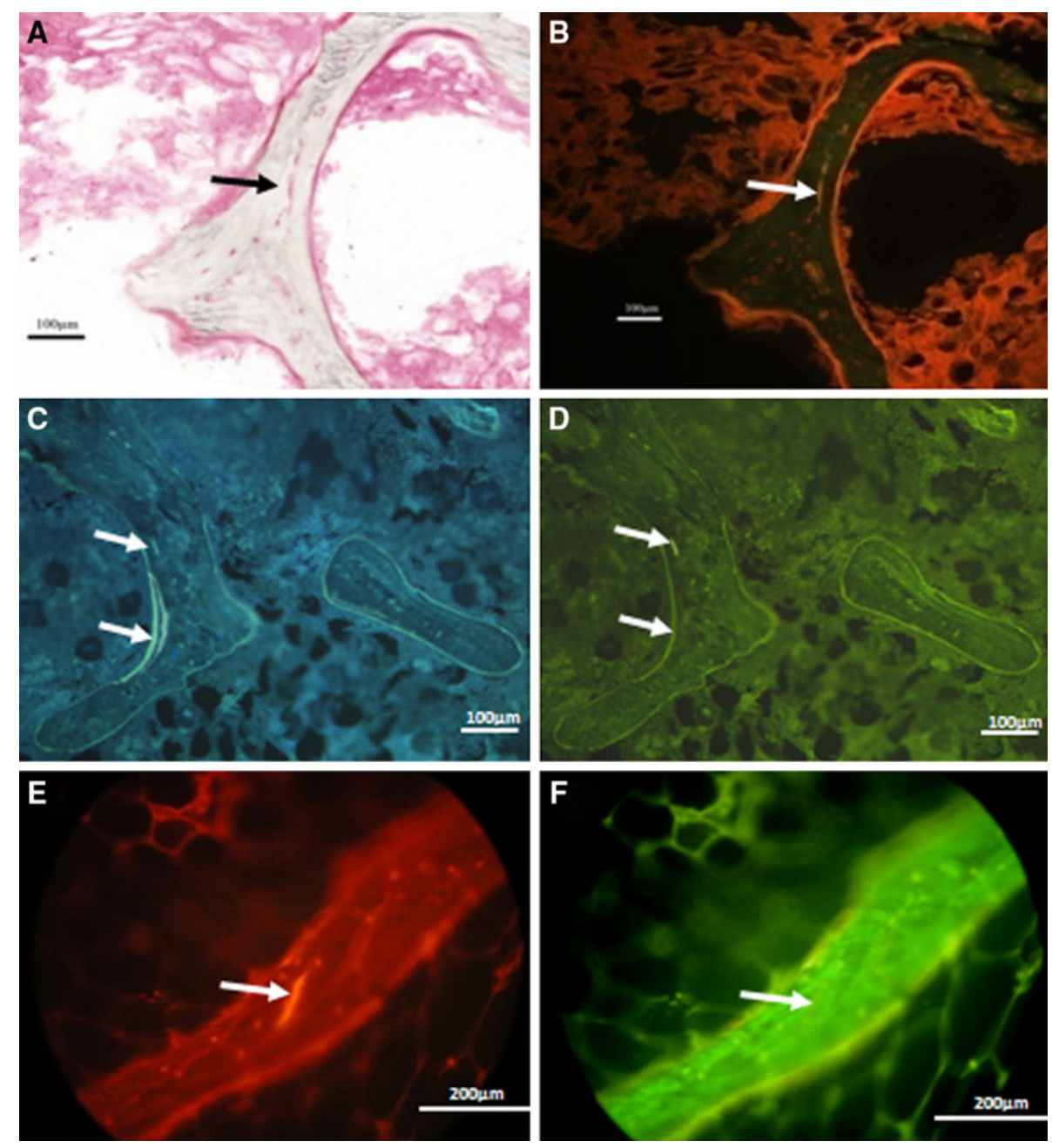

the only study comparable to ours, Stepan et al. [41] measured transiliac crest biopsies from 38 women who had been treated with alendronate for an average of 5 years, and compared them to a control sample of 28 women who were treatment naive. They found a difference in the mean crack length $(\mu \mathrm{m})$ of approximately $47 \mu \mathrm{m}$ between the treatment-naive and alendronatetreated women. The crack length they observed was shorter than in our study. This may be explained by falsepositive findings. Indeed, some smaller structures-like osteocyte canaliculae-can be reminiscent of the appearance of cracks and can be mistaken for cracks. Microdamage was also rare in cortical bone, and only three samples had at least one observable microcrack [36]. This may also stem from the type of bone we studied. In animal models, it has been shown that most microcracks are observed in long weight-bearing bones, e.g., the femurs. In addition, the clinical significance of microcracks may differ between cortical and trabecular bone and whether the microdamage occurs under physiological or experimental conditions. Indeed, microdamage induced by fatigue loading impairs bone mechanical properties, whereas pre-existing physiological microdamage observed in vertebrae does predict mechanical properties [37].

It is important to remember that alcohol influences bone mechanical properties, hence crack propagation. Therefore, we used a combination of calcein green at $0.5 \mathrm{mM}$ concentration and xylenol orange at $5 \mathrm{mM}$, which preserved bone as much as possible, and also allowed the use of other techniques to explore bone quality (data not shown: microradiography [42], Fourier transform infrared microscopy [43], microhardness [44]).

In conclusion, this methodological approach allowed the detection and the identification of both microdamage (linear, diffuse and cross-hatched)_pre-existing in vivo in bone, or induced by the technique or mechanical loadingand tetracycline labels as demethylchlortetracycline. Calcein green at $0.5 \mathrm{mM}$ concentration and xylenol orange at $5 \mathrm{mM}$ seem to be the most appropriate dyes to be able to study both microcracks and histomorphometry because they preserve the tetracycline labels. 
Acknowledgments The authors wish to acknowledge Dr Anna Bencsik, from histology dept of Anses Lyon laboratory for her assistance in the preparation of the manuscript, and Jean-Paul Roux, from INSERM UMR 1033 for his technical assistance.

Conflict of interest All the authors state that they have no conflicts of interest.

\section{References}

1. Fazzalari NL, Forwood MR, Smith K, Manthey BA, Herreen P (1998) Assessment of cancellous bone quality in severe osteoarthrosis: bone mineral density, mechanics, and microdamage. Bone 22:381-388

2. Norman TL, Wang Z (1997) Microdamage of human cortical bone: incidence and morphology in long bones. Bone 20:375-379

3. Schaffler MB, Choi K, Milgrom C (1995) Aging and matrix microdamage accumulation in human compact bone. Bone 17:521-525

4. Vashishth D (2007) Hierarchy of bone microdamage at multiple length scales. Int J Fatigue 29:1024-1033

5. Wenzel TE, Schaffler MB, Fyhrie DP (1996) In vivo trabecular microcracks in human vertebral bone. Bone 19:89-95

6. Burr DB, Stafford T (1990) Validity of the bulk-staining technique to separate artifactual from in vivo bone microdamage. Clin Orthop 260:305-308

7. Martin RB, Yeh OC, Fyhrie DP (2007) On sampling bones for microcracks. Bone 40:1159-1165

8. Diab T, Vashishth D (2007) Morphology, localization and accumulation of in vivo microdamage in human cortical bone. Bone 40:612-618

9. Vashishth D, Koontz J, Qiu SJ, Lundin-Cannon D, Yeni YN, Schaffler MB, Fyhrie DP (2000) In vivo diffuse damage in human vertebral trabecular bone. Bone 26:147-152

10. Fazzalari NL, Forwood MR, Manthey BA, Smith K, Kolesik P (1998) Three-dimensional confocal images of microdamage in cancellous bone. Bone 23:373-378

11. Burr D (2003) Microdamage and bone strength. Osteoporos Int $14: 67-72$

12. Burr DB, Turner CH, Naick P, Forwood MR, Ambrosius W, Hasan MS, Pidaparti R (1998) Does microdamage accumulation affect the mechanical properties of bone? J Biomech $31: 337-345$

13. Diab T, Vashishth D (2005) Effects of damage morphology on cortical bone fragility. Bone 37:96-102

14. Akkus O, Knott DF, Jepsen KJ, Davy DT, Rimnac CM (2003) Relationship between damage accumulation and mechanical property degradation in cortical bone: microcrack orientation is important. J Biomed Mater Res A 65:482-488

15. Diab T, Condon KW, Burr DB, Vashishth D (2006) Age-related change in the damage morphology of human cortical bone and its role in bone fragility. Bone 38:427-431

16. Lee TC, Mohsin S, Taylor D, Parkesh R, Gunnlaugsson T, O'Brien FJ, Giehl M, Gowin W (2003) Detecting microdamage in bone. J Anat 203:161-172

17. Lee TC, Myers ER, Hayes WC (1998) Fluorescence-aided detection of microdamage in compact bone. J Anat 193:179-184

18. O'Brien FJ, Brennan O, Kennedy OD, Lee TC (2005) Microcracks in cortical bone: how do they affect bone biology? Curr Osteoporos Rep 3:39-45

19. O'Brien FJ, Taylor D, Dickson GR, Lee TC (2000) Visualisation of three-dimensional microcracks in compact bone. J Anat $197: 413-420$
20. Schaffler MB, Pitchford WC, Choi K, Riddle JM (1994) Examination of compact bone microdamage using back-scattered electron microscopy. Bone 15:483-488

21. O'Brien FJ, Hardiman DA, Hazenberg JG, Mercy MV, Mohsin S, Taylor D, Lee TC (2005) The behaviour of microcracks in compact bone. Eur J Morphol 42:71-79

22. Mohsin S, O'Brien FJ, Lee TC (2006) Microcracks in compact bone: a three-dimensional view. J Anat 209:119-124

23. McDonnell P, McHugh PE, O’Mahoney D (2007) Vertebral osteoporosis and trabecular bone quality. Ann Biomed Eng 35:170-189

24. Moore TL, Gibson LJ (2002) Microdamage accumulation in bovine trabecular bone in uniaxial compression. J Biomech Eng 124:63-71

25. Mori S, Harruff R, Ambrosius W, Burr DB (1997) Trabecular bone volume and microdamage accumulation in the femoral heads of women with and without femoral neck fractures. Bone 21:521-526

26. Shi X, Liu XS, Wang X, Guo XE, Niebur GL (2010) Effects of trabecular type and orientation on microdamage susceptibility in trabecular bone. Bone 46:1260-1266

27. Wang X, Masse DB, Leng H, Hess KP, Ross RD, Roeder RK, Niebur GL (2007) Detection of trabecular bone microdamage by micro-computed tomography. J Biomech 40:3397-3403

28. Yeni YN, Hou FJ, Ciarelli T, Vashishth D, Fyhrie DP (2003) Trabecular shear stresses predict in vivo linear microcrack density but not diffuse damage in human vertebral cancellous bone. Ann Biomed Eng 31:726-732

29. Burr DB, Hooser M (1995) Alterations to the en bloc basic fuchsin staining protocol for the demonstration of microdamage produced in vivo. Bone 17:431-433

30. Wasserman N, Brydges B, Searles S, Akkus O (2008) In vivo linear microcracks of human femoral cortical bone remain parallel to osteons during aging. Bone 43:856-861

31. Lee TC, Arthur TL, Gibson LJ, Hayes WC (2000) Sequential labelling of microdamage in bone using chelating agents. J Orthop Res 18:322-325

32. Zarrinkalam KH, Kuliwaba JS, Martin RB, Wallwork MA, Fazzalari NL (2005) New insights into the propagation of fatigue damage in cortical bone using confocal microscopy and chelating fluorochromes. Eur J Morphol 42:81-90

33. Chavassieux P, Buffet A, Vergnaud P, Garnero P, Meunier PJ (1997) Short-term effects of corticosteroids on trabecular bone remodeling in old ewes. Bone 20:451-455

34. Dickson GR (1984) Methods of calcified tissue preparation. Elsevier, Amsterdam

35. Frost HM (1960) Presence of microscopic cracks in vivo in bone. Henry Ford Hosp Med Bull 8:27-35

36. Chapurlat RD, Arlot M, Burt-Pichat B, Chavassieux P, Roux JP, Portero-Muzy N, Delmas PD (2007) Microcrack frequency and bone remodeling in postmenopausal osteoporotic women on long-term bisphosphonates: a bone biopsy study. J Bone Miner Res 22:1502-1509

37. Follet H, Viguet-Carrin S, Burt-Pichat B, Depalle B, Bala Y, Gineyts E, Munoz F, Arlot M, Boivin G, Chapurlat RD, Delmas PD, Bouxsein ML (2010) Effects of preexisting microdamage, collagen cross-links, degree of mineralization, age, and architecture on compressive mechanical properties of elderly human vertebral trabecular bone. J Orthop Res. doi:10.1002/jor.21275

38. Arlot ME, Burt-Pichat B, Roux JP, Vashishth D, Bouxsein ML, Delmas PD (2008) Microarchitecture influences microdamage accumulation in human vertebral trabecular bone. J Bone Miner Res 23:1613-1618

39. Sun TC, Mori S, Roper J, Brown C, Hooser T, Burr DB (1992) Do different fluorochrome labels give equivalent histomorphometric information. Bone 13:443-446 
40. O'Brien FJ, Taylor D, Lee TC (2002) An improved labelling technique for monitoring microcrack growth in compact bone. J Biomech 35:523-526

41. Stepan JJ, Burr DB, Pavo I, Sipos A, Michalska D, Li J, Fahrleitner-Pammer A, Petto H, Westmore M, Michalsky D, Sato M, Dobnig H (2007) Low bone mineral density is associated with bone microdamage accumulation in postmenopausal women with osteoporosis. Bone 41:378-385

42. Bala Y, Farlay D, Delmas PD, Meunier PJ, Boivin G (2010) Time sequence of secondary mineralization and microhardness in cortical and cancellous bone from ewes. Bone 46:1204-1212
43. Farlay D, Panczer G, Rey C, Delmas PD, Boivin G (2010) Mineral maturity and crystallinity index are distinct characteristics of bone mineral. J Bone Miner Metab 28:433-445

44. Bala Y, Boivin G, Simi C, Ste-Marie LG, Delmas PD, Meunier PJ (2006) The microhardness of bone is only partly explained by its degree of mineralization in control and osteoporotic subjects. J Bone Miner Res 21:S332 (abstract M019) 